\title{
3. Music and Language in Duna Pikono
}

\author{
Kirsty Gillespie and Lila San Roque
}

\section{Introduction}

The relationship between music and language has been a topic of scholarship for many years, across the academic world. In the Duna "sung story" genre of pikono, systems of music and language are interdependent and it is this relationship that our chapter explores.

In keeping with the topic of this volume, our discussion only relates to pikono that is sung. Sung pikono is considered by the Duna to be the height of the craft, and this is the mode of delivery for male performances. Women also create pikono, however the performance context and their delivery of pikono is much different. Men typically sing pikono to groups of men in men's houses at night (see Kendoli, this volume). Women, on the other hand, tell (rather than sing) pikono to other women or to children, often in their homes, as reported by Modjeska (1977:332). We have found that often the pikono told by women feature sections of sung text that most commonly illustrate a musical event of some kind, such as a courting song or a lament, which occurs within the story. Predominantly, however, women's pikono are in spoken form, and as such will not be discussed here. ${ }^{1}$

We focus on men's sung performance of pikono, but in particular we examine a performance of pikono by one man, Kiale Yokona, whom we met in March 2005 at Hirane parish ${ }^{2}$ in the Kopiago area, where we were both conducting our doctoral research. Kiale arrived from the neighbouring parish of Mbara, and word quickly spread that he would be telling a pikono at the Hirane men's house that night. We dropped by the men's house briefly and, conforming to the gender rules governing the space, arranged for him to perform for us the next evening in another location. The result was a recording of a pikono of just under three

\footnotetext{
1 Another issue for further exploration concerns how the predominantly sung genre of pikono overlaps with the spoken genre of hapia po, and how these categories are defined and mobilized by different Duna individuals and communities.

2 The term "parish" was introduced to Melanesian anthropology by Hogbin and Wedgwood, who define it as "the largest local group forming a political unit," elaborating that "each parish, then, is composed of persons associated with a certain tract of land, bearing a distinctive name" (1953:243, 253). In using the term parish we follow other scholars of Duna culture, who in turn followed terminology used by Modjeska (Haley 2002:15). Parish divisions were present in pre-contact times, and are known in Duna as rindi ('land(s)'). See Modjeska (1977), Stürzenhofecker (1998), Haley (2002), and Strathern and Stewart (2004) for further information concerning Duna parish divisions and membership rights and responsibilities.
} 
hours in length ${ }^{3}$ made by Gillespie, which has been transcribed and translated in its entirety by San Roque and Kenny Kendoli, with assistance from Richard Alo. The portrait of Kiale shown in figure 1 was taken the day after this performance.

This pikono performance is used as a point of departure to discuss the structure of pikono, both musical and linguistic, and how it relates to other Duna genres. In particular, we point out the presence of repetition which comes about through the use of "praise name" sequences, the process of which is known in the Duna language as ipakana yakaya (see Haley 2002:6-10, 117-25; Stewart and Strathern 2005:87-88, 93; Gillespie 2010a, 2010b). We also explore the functions of identifiable parts of the Duna pikono structure, and discuss the audience responses that performances elicit.

\section{Structural units within pikono}

We begin with a description of what a typical pikono sounds like. The musical element under discussion here is melodic contour. The term "melody" will not be used, as pikono does not have a defined sequence of pitches that can be identified as constituting a melody, but rather, a defined sense of pitch shape and direction. As pikono is essentially a solo tradition, there is no form of harmony to be analysed. In addition, as is typical of most Duna ancestral genres, the genre is non-metred, and so neither will rhythm be discussed. The focus then is on pitch and its relationship to text.

Pikono can be broken down into units that we, for the purposes of this discussion, have called phrases, which generally consist of several lines. ${ }^{4}$ Phrases and the lines therein are demarcated in terms of melodic contour, pauses, and textual structure. The final word in a phrase normally has a sustained final vowel, or has a vowel added to it (e.g., $o$ or $e$ ). In Kiale's performance, this sung vowel often leads into a hum as Kiale closes his lips and maintains a voiced airflow for a few moments before taking a breath and beginning the next phrase. In his performance, a single phrase is typically ten to twenty seconds long, and rarely more than thirty seconds. Textually, it is not unusual for one pikono phrase to comprise what is basically a single sentence, with additional exclamations, repetitions, and narrative expressions.

3 There were three short breaks in this performance, the first two instigated by the performer and audience, the third to replace the battery in the recording device. The performance was thus recorded in four parts of varying lengths: (a) c. $30 \mathrm{~min}$; (b) c. $1 \mathrm{hr} 18 \mathrm{~min}$; (c) c. $21 \mathrm{~min}$; and (d) c. $39 \mathrm{~min}$.

4 Unlike the general understanding of what constitutes a "phrase" in vocal studies, the unit here is not defined by breath. 


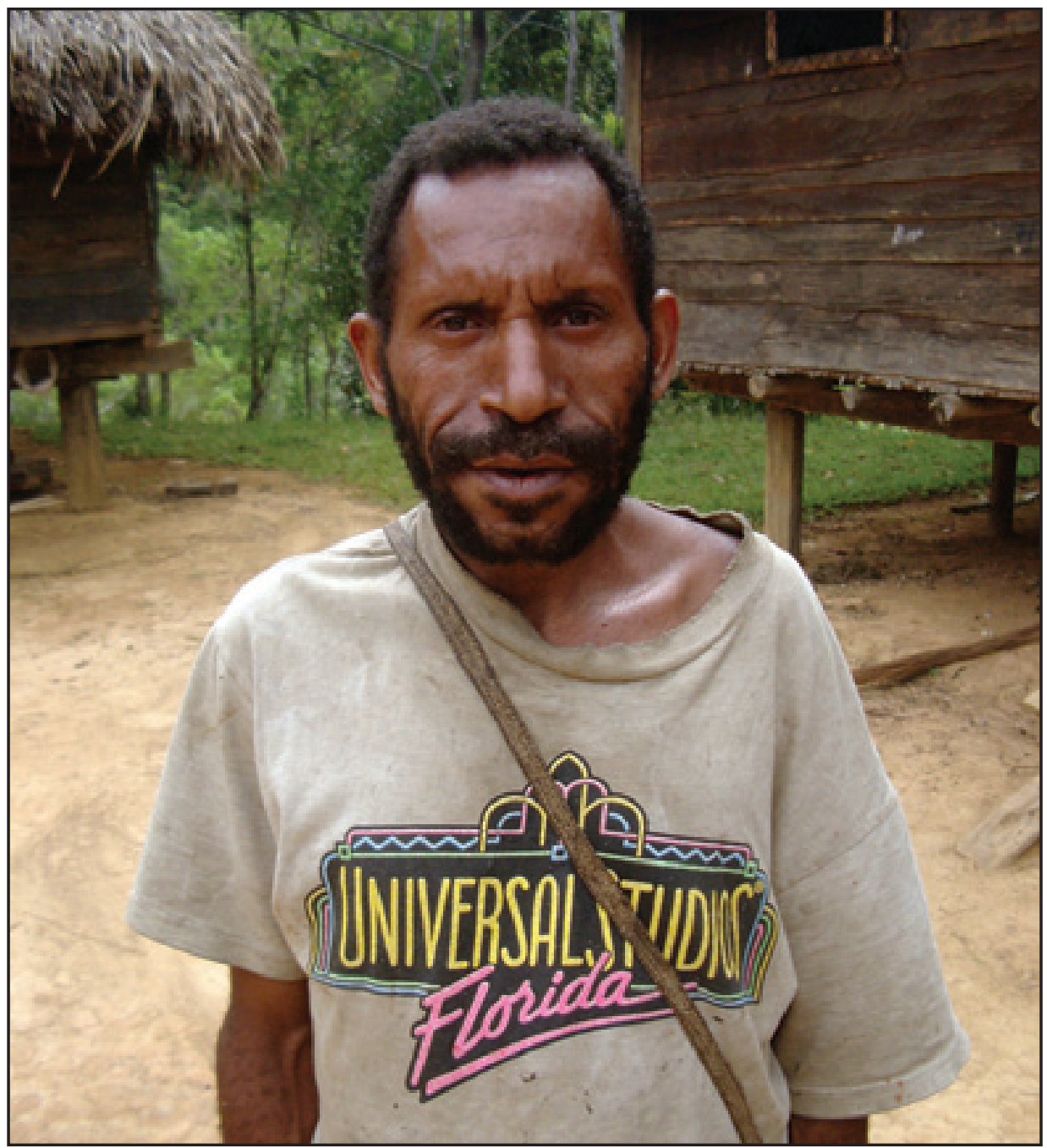

Figure 1. Kiale Yokona at Hirane parish, March 2005 (photo by Kirsty Gillespie).

Each pikono phrase can be subdivided into two sections, the first we call the "descent," and the second we call the "ground." We have not encountered any indigenous terms that conventionally identify and label these sections. ${ }^{5}$ Figure 2 shows the pitch trace of the pikono phrase that we discuss in detail in the following section, with line numbers corresponding to the text lines shown in text 1 . The overlaid arrows schematically represent the characteristic pitch movement of the descent and ground sections of a typical phrase.

5 In her initial musical analyses of pikono, Gillespie gave these two sections the working labels "body" and "coda" respectively. However, these terms appear hierarchical, suggesting that the second section is not as significant as the first-almost peripheral to it—which is not the case. For that reason, these labels are no longer used. 


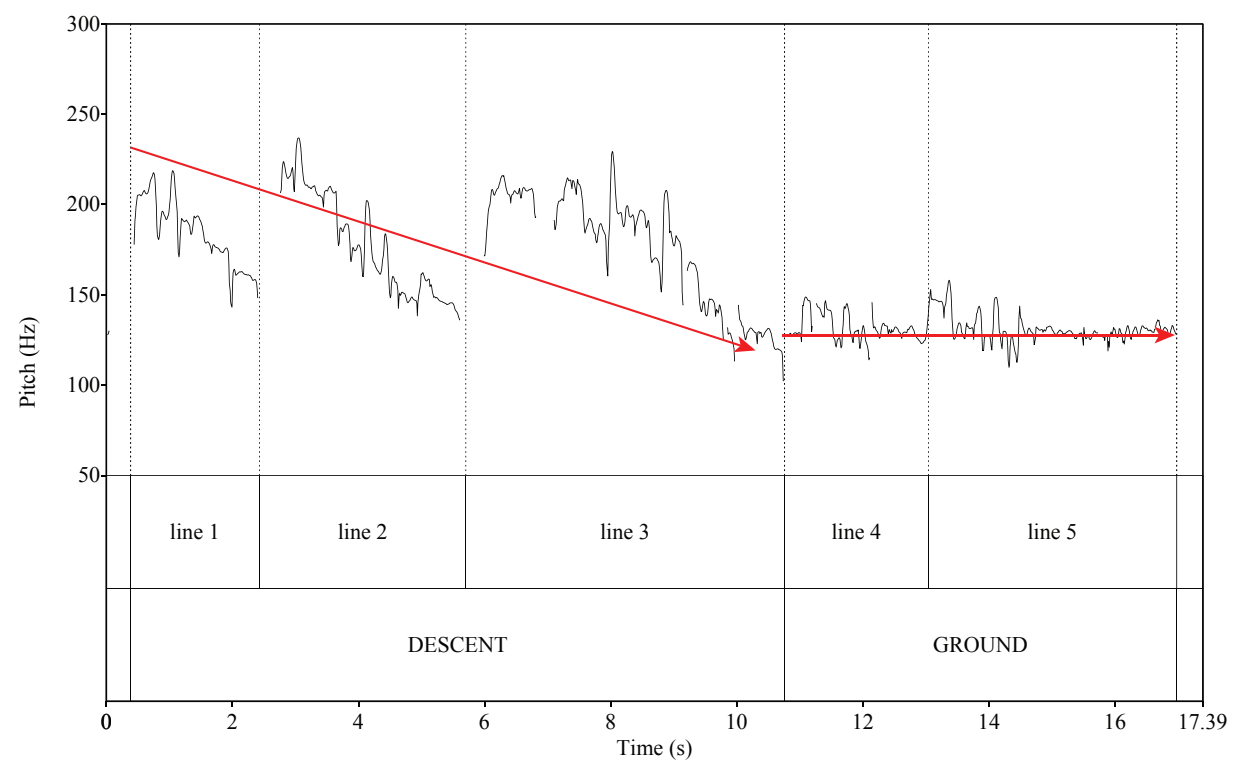

Figure 2. Pitch trace of the pikono phrase shown in text 1 , showing the descent and ground sections (drawn using the program Praat).

The descent marks the beginning of the pikono phrase. It is named such for its melodic contour: generally it begins around a fifth or sixth above the tonal centre (sometimes more, as the pikono performance progresses) and gradually descends to that tonal centre, with some melodic diversions along the way. There is often a brief dip down to a tone just below this tonal centre and back again to mark the arrival of the ground section, as can be seen in figure 2. This descent is one of the most distinctive characteristics of the genre-as most Duna song genres exhibit a range of around two whole tones, pikono is the genre with the widest melodic range. ${ }^{6}$

The second section of the pikono phrase we have called "ground." This label is intended to reflect both the predominance of the tonal centre (the "foundation" of the melodic contour) and the focus on landscape features within the text that often occurs at this point. Beginning on the tonal centre (where the previous section concluded), this section is marked by repetition that focuses on the tonal centre, briefly visiting the tones on either side of it. In cipher notation, this pattern can be generally represented as $121-21$, where 1 is the tonal centre, 2 a step above it, and -2 a step below. Often tone 3 is also employed, and tone 2 is more often used than tone -2 . Cipher notation, also used by Jacqueline Pugh-Kitingan in her description of song of the neighbouring Huli people (Pugh-Kitingan 1981),

6 This statement excludes genres that incorporate dance, such as mali, in which song text is punctuated by falsetto calls an octave above. 
is helpful to describe the pitches employed in Duna pikono, as they are not based on a pre-existing scale or form of tuning, but rather on their relationship to each other (Chenoweth 1969).

While the melodic direction of the descent section can be generally anticipated, the descent of each pikono phrase is different. The ground section, however, presents a repeated and predictable melodic formula that occurs in other Duna genres, most notably in women's laments. Working in tandem with this, textual lines within the descent section are normally quite different from each other, with little repetition occurring from line to line. However the ground section is built around a repetitive textual frame (commonly modelled on the final line of the descent section), containing parallel iterations of specialized kẽiyaka vocabulary terms.

Duna kẽiyaka vocabulary is identified and discussed by Haley as "a special esoteric vocabulary of praise names and honorific forms" (Haley 2002:132). Kéiyaka terms for a single item are often phonologically very similar to each other, differing with respect to a single phoneme or syllable. In pikono text, kẽiyaka terms can be used in a variety of ways, for example, replacing common vocabulary items in the descent section of a phrase or enriching the identity and history of characters in the narrative (see Kendoli, this volume). In the ground section of a pikono phrase, kẽiyaka occur as part of a sequence, in which several kẽiyaka terms for a single item (typically a landscape feature) are used in a conventional order (see also Strathern and Stewart, this volume). A kẽiyaka normally occurs within a framing phrase, and at each iteration of the frame a new kẽiyaka is substituted for the one preceding. This distinctive textual and melodic pattern is termed ipakana yakaya, ${ }^{7}$ which has been described by Duna speakers as "counting rivers and mountains" (see Kendoli, this volume).

\section{A pikono phrase close-up}

Text 1 shows the text and English translation of a single pikono phrase from Kiale's performance. At this point in the story, one of the main female characters, Kundaleme, is trying to persuade one of the heroes, Kaloma Koli, to go on a journey with her to meet the spirit of his close companion, Sayanda Sayape (who has recently been killed by man-eating giants). She explains that Sayanda Sayape is going to appear to him, accompanied by a group of female spirits, and deliver an important message. We have divided the text into lines according to a combination of features, including breath breaks, grammatical units, and melodic contour. Kẽiyaka terms are underlined in the Duna text and appear in

7 An alternative earlier spelling of this is ipakana yakaiya (as used in Haley 2002). 
italics in the English translation, as do exclamations and narrative markers. ${ }^{8}$ Text in curly brackets shows spoken audience responses, a topic that will be returned to later in this chapter.

\section{Text 1. Text and translation of a single phrase from Kiale's performance. An audio file of this example can be found in online item 2 .}

hiwakuya kata yaritia
ake yaritia sopa aipe ruwanania
mm yaritia sayanda sayape yaritia etona
pei popo ndu sutia kena
palu pelei popo ndu sutia kenania
yana ayano popo ndu sutia kenania
\{keno nganda!\}

\author{
they are all coming out it was heard \\ what then it was heard who is below, he will speak \\ mm it was heard Sayanda Sayape it was heard across \\ there you will see the pei Hewa popo feathers shake \\ you will see the palu pelei Hewa popo feathers shake \\ you will see the yana ayano Hewa popo feathers \\ shake \\ \{we two will go! \\ (from recording by Kirsty Gillespie 2005:vol. 3.2, \\ track $3,0.27-0.44)$
}

As can be seen in text 1, kẽiyaka vocabulary is introduced towards the end of the third line. The "framing" text here (popo ndu sutia kena(nia)) itself includes a kẽiyaka word, popo, which is a poetic term for a fluffy kind of cassowary feather. The cassowary feathers are further identified as coming from the (low altitude) Hewa area, one of the Duna's neighbouring language groups, and this is the place that is consecutively named in the ground section of this phrase. The kêiyaka terms create some assonance with repetitions of certain sounds and sound sequences, for example $p, p-l-$, and yan-. Note also that the textual frame is not exactly replicated, as the morpheme -nia' is added to the verb kena ('will see') in the fourth and fifth lines, but not present in the third. It is in fact common practice for the framing text to differ slightly from line to line.

Figure 3 represents an approximation of the pitch contour of this phrase.

In figure 3, the descent section comprises the first two lines, whilst the ground section comprises the final line. The tonal centre is $\mathrm{C}$; the descent begins approximately a sixth above this centre, descending by the end of the second line to the tonal centre, touching, as is typical, on the (semi)tone below this centre. The ground section then begins, reinforcing the tonal centre and the tone above it, D (these pitches can be represented in cipher notation as 1 and 2, respectively). This same pattern of low tones in a restricted range characterizes the melodic patterning of the ipakana yakaya process, and is particularly reminiscent of the Duna lament song genre khene ipakana (see Stürzenhofecker 1998:43-46; Stewart and Strathern 2000:92-94; Gillespie 2010a; 2010b:85-121; Kendoli, this volume).

\footnotetext{
8 As in the sung story genres of other language groups of the region, there are certain formulaic markers that recur in sung pikono texts and frame it as a narrative. Different performers use slightly different markers (or combinations of markers), although they all normally highlight the fact that this is a story that is being told now, about long-ago things that have been described before. In the performance under discussion, the marker Kiale uses most commonly is yaritia, which means roughly 'it was heard'.

9 This morpheme occurs after verbal inflection and emphasizes the speaker's conviction in the truth of their utterance.
} 
Figure 3. Pitch contour of the phrase in text 1.

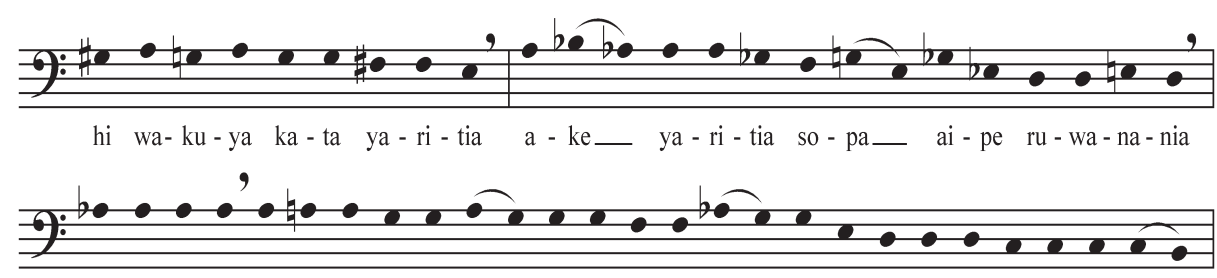

mm ya - ri - tia sa-ya-nda sa-ya-pe_ ya-ri-tia e - to - na pei po-po ndu su-tia ke-na_

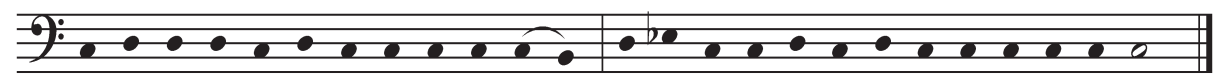

pa $=\underline{\text { lu }}$ pe $=\underline{\text { lei }}$ po $=$ po ndu su-tia ke-na-nia ya $=\underline{\text { na }} \underline{\mathrm{a}}=\mathrm{ya}=\underline{\text { no }}$ po-po ndu su-tia ke-na-nia

This example can be considered as a typical pikono phrase. In particular, note that the first kẽiyaka of the sequence appears at the end of the descent section as the singer approaches the tonal centre (and the ground section). The repetitions of alternative kẽiyaka, each set in a recurring textual phrase introduced with the first kẽiyaka, and featuring the melodic repetition of tones 1 and 2, are the formula of the ground section (see also Sollis, this volume, concerning melodic parallelism across the ground sections of adjacent pikono phrases).

\section{Engaging with the narrative}

We turn now to a consideration of pikono as narrative performance designed to create and maintain audience engagement, and provoke appreciative and heartfelt response (see also Strathern and Stewart, this volume, concerning pedagogic attributes of pikono). We reflect upon possible contrastive functions of the descent and ground sections of the pikono phrase in regard to this and argue here that they can be viewed as functionally distinct for much of the performance. The focus of the descent section is generally on narrative content, advancing the action of the story and maintaining a dynamic thread of events. The ground section encourages an expanded appreciation of imagery that attaches to these events, an increased absorption in the perceptual world of the characters, and perhaps cues an experience of the performance as something that is personally moving, evoking one's own memories and experiences.

It is generally true to say that each phrase in a pikono introduces a new item or activity, and advances a notch in the narrative. Throughout most of Kiale's pikono text, it is within the second and/or third lines of the descent that the plot or action of the story progresses. Since the ground section of the pikono is built around a repetitive sequence it cannot normally introduce new narrative content. 
Looking at text 1 , the first line is a recapitulation of the activity described in the preceding phrase; the first word hiwaku- ('all come out') repeats the verb that concluded the previous ground section. ${ }^{10}$ Thus, the first line of the descent links the coming activity to what has just occurred. The second line of this phrase starts with a semantically fairly empty refrain ake yaritia (translated here as 'what then, it was heard') that Kiale uses many times in his performance, most frequently at the beginning of the second line of the descent, as seen here. The following question, sopa aipe 'who (is) below?', is also a stock phrase, signifying to the audience that we are about to hear the name of a character in the story and find out what he or she is up to. This motif only occurs in the descent section of pikono phrases, as this is where new characters are brought into the story or where a known character reappears in the narrative. In this case we hear (through the words of Kundaleme) that the spirit of Sayanda Sayape is going to communicate with Kaloma Koli, coming out dancing to meet him.

It can be seen from text 1 that "what happens next" is not necessarily transparently articulated, but may be implied or interpreted through a combination of conventional and/or story-specific associations, as well as a knowledge of kẽiyaka vocabulary. At the basic level of lexical recognition, a hearer needs to know (or deduce) the kẽiyaka for Hewa and for cassowary feathers. These terms are mutually re-enforcing and informative, as cassowaries are held to be numerous in the lowland Hewa area, and this collocation of "[Hewa kẽiyaka] popo" is additionally a recognizable trope in Kiale's performance. A listener further needs to make the association that Sayanda Sayape is adorned with cassowary feathers, which is suggested by cues earlier in the story and other recurring metaphors, as well as knowledge of the practice of body decoration generally (see also Sollis, this volume).

The image introduced in the descent and reiterated in the lines of the ground section is also potentially complex. The description of the feathers' movement evokes the dancing movement of Sayanda Sayape, but can also allude to the idea that he travels from the land of the dead on a swaying and shaking cane bridge. The kẽiyaka for feathers used here (popo) also references a more standard vocabulary item for gathering mist or cloud. The repetition of this line in the ground section perhaps allows time for a fuller comprehension and envisioning of both the narrative activity and rich poetic image that is described. Kaloma Koli's beloved friend will come back to him at last, suspended in a mist of trembling feathers.

It can be noted that the lines here specifically describe a visual image, presenting the movement of the feathers as a complement clause of the verb kena '(you)

10 This "tail-head linkage" (de Vries 2005) - i.e., the repetition of the preceding final verb to begin a new sentence-is a very common pattern in Duna narrative generally (see also Giles 1972). 
will see'. These words are spoken in the story by Kundaleme to Kaloma Koli, but as there is no frame for this reported speech (e.g., '... she said') included in these lines, ${ }^{11}$ it is possible to identify the "seer" as not only Kaloma Koli but also the audience members of the pikono performance, being spoken to by Kiale (see also Borchard and Gibbs, this volume).

This turning towards the personal witnessing of the image described may also be reflected in the semantics of grammatical markers that occur on final verbs. It is generally in the ground section, or the final transitional line of the descent, that we reach the final verb of the major sentence of the phrase. In ordinary spoken Duna, final verbs are commonly marked for the grammatical category of "evidentiality"; that is, they can encode the information source that the speaker has for their utterance (see, e.g., Chafe and Nicholls 1986, Aikhenvald 2004). The verbal marker -tia, for example, normally indicates that the speaker or hearer saw the event that is being described. In Duna narrative, the viewpoint of a main character can be conventionally adopted as the information source that is indicated. For example, in conversation a speaker typically uses -tia to mark a statement describing something that they have personally witnessed, but in telling a story they can use it to mark events that the main character witnesses in the course of the narrative (see San Roque 2008:309-18, 333, 377, 388, 430-35 for further discussion and examples).

The verbal markers used in pikono, particularly as they occur in the ground section, thus encourage the hearers to place themselves as direct perceivers of the events, absorbed in the world that is being sung. In contrast to this, the more explicitly narrative marker yaritia ('it was heard') as deployed by Kiale in this performance occurs frequently in the descent section, but is relatively rare in the ground section. At the commencement of a phrase and in presenting new narrative content, Kiale reminds the audience that it is a story they are listening to, but in the recurring imagery of the ground section, Kiale invites the audience to identify themselves as perceptual experiencers of the narrated phenomena rather than of a narrative performance.

The close resemblance in melodic and textual structure of the ground section of pikono with the Duna lament genre of khene ipakana highlights a potential for further emotional and personal engagement. Such engagement may include the identification of death and loss in the story with one's own experiences of bereavement (see Kendoli, this volume).

11 In conversational Duna and in most Duna narrative speech, it would be usual to express words spoken by another as complement clauses within bracketing forms of the (irregular) verb ruwa- ('say'). 


\section{Sex and the moon}

We have focused so far on phrases in which the descent section introduces new information to the story, and these make up the majority of Kiale's pikono. There are several occasions, however, in which a new phrase does not advance the plot, but in which the descent section closely mirrors that of the previous phrase as a particular image or theme is expanded and reiterated in new ways. This is most clearly the case in chains of phrases that describe the movement of light as day turns to night and/or night to day.

There are two such sequences in Kiale's performance, the first detailing the travelling of the setting sun (lasting approximately 3.5 minutes), the second describing the shifting light of the moon (lasting approximately 4.5 minutes) and then the spreading light of dawn the following day (lasting approximately 2.5 minutes). Both of these sequences begin immediately after a male and female heroine have been dancing together at a public event and are either about to start or have already started on an overnight journey.

In the phrases of these sections, descent sections are comparatively brief, while ground sections are typically extended. The introductory text of the descent is similar from phrase to phrase, providing some reference to the movement of the light or the astral body itself, while the ground section details the names of the places where the light falls, and commonly details an activity that becomes visible there. ${ }^{12}$ The text of a phrase within one of these sequences in Kiale's performance is shown in text 2 . At this point Kiale is describing the bright light of a full moon, falling upon unsuspecting young women in its path.

\section{Text 2. Kiale's description of the full moon's bright light falling upon young women. An audio file of this example can be found in online item 3 .}

keya hoyaki iwakurane yaritia
e yaritia awi hutia kia hini papa hani
no yão reinia riya etopi hutia kia hini
papa hanirane
$\{$ continuing comments\}
$\frac{\text { kura akura pakura }}{\text { kia hilipi papa hanirane } \frac{\text { ramapu }}{\text { koa }} \text { hutia }}$
\{indecipherable comment\} \{ndu
narayani\}

keya hoyaki iwakurane yaritia no yão reinia riya etopi hutia kia hini
papa hanirane

\{continuing comments kura akura pakura rilipi ramapu hutia narayani\} looking to this side it sinks down closer it was heard ah it was heard these awi Hirane ones right here try to cover themselves with fern fronds I'm sitting with nothing on they cry, these etopi Hirane ones tried to cover themselves with fern fronds

these kura Hirane akura Hirane pakura Hirane rilipa Hirane ramapu Hirane ones tried to cover themselves with fern fronds \{there's not one [woman] here!\}

(from recording by Kirsty Gillespie 2005:vol. 3.2, track 3, 3.51-4.02)

12 This can be seen as a form of higher-level parallelism, in which the descent section provides framing text that is repeated in the descent of the following phrases, and the theme of the ground section remains fairly constant, with only the identity of the places changing significantly. 
It can be noted that, rather than changing one kẽiyaka term within each line (as was seen in text 1), the final line of this phrase contains five kẽiyaka terms for Hirane parish listed one after the other. This is a common feature of phrases within the moon/sun sequences, in which up to seven separate kẽiyaka may be condensed into a single iteration of the framing text. This example also clearly shows cumulative sound repetition features, especially in the three adjacent terms kura, akura, pakura; this can also be described as a form of parallelism at the level of individual sounds, as kura remains constant while the first syllable of the word changes. Figure 4 represents an approximation of the pitch contour of the last two lines of this phrase.

Figure 4. Pitch contour of the last two lines of the phrase in text 2.

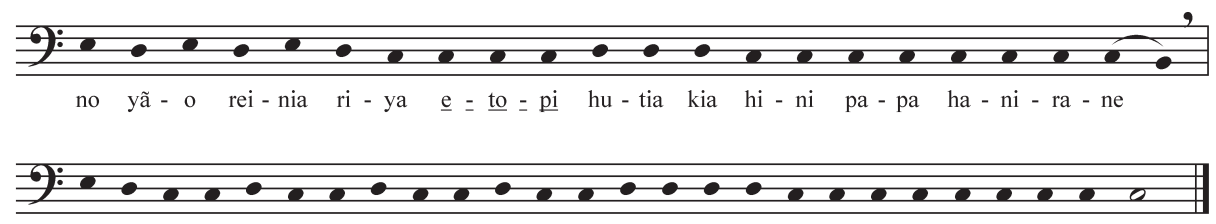

$\underline{\mathrm{ku}}=\underline{\mathrm{ra}} \underline{\mathrm{a}}=\underline{\mathrm{ku}}=\underline{\mathrm{ra}}$ pa $=\underline{\mathrm{ku}}=\underline{\mathrm{ra}} \underline{\mathrm{ri}}=\underline{\mathrm{li}}=\mathrm{pi} \underline{\mathrm{ra}}=\underline{\mathrm{ma}}=\underline{\mathrm{pu}}$ hu-tia kia hi-ni pa-pa ha-ni-ra-ne kao-e

This example clearly shows melodic repetition which is typical of musical settings of kẽiyaka. Four of the five kẽiyaka in the sequence of the last line feature the exact same patterning. Whilst the first kẽiyaka of this sequence, kura, descends to the tonal centre over the tones 3 and 2, the next four keiyaka-each three syllables in length - are set to the pattern 112 (that is, two syllables on the tonal centre and then one a step above). It is also apparent that the textual setting for this kẽiyaka sequence and the line above it_hutia kia hini papa hanirane-are identical, with the first three syllables on the second tone (2) and the remainder on the tonal centre (1). Figure 5 shows figure 4 represented in cipher notation with the distinctive 112 pattern shown in bold type and underlined.

Figure 5. Pitch contour of figure 4, shown in cipher notation.

no yã-o rei-nia ri-ya e-to-pi hu-tia kia hi-ni pa-pa ha-ni ra-ne

$\begin{array}{lllllllllllllllllllll}3 & 2 & 3 & 2 & 3 & 2 & 1 & 1 & 1 & 1 & 2 & 2 & 2 & 1 & 1 & 1 & 1 & 1 & 1 & 1 & 1\end{array}$

$\underline{k u-r a} \underline{a-k u-r a}$ pa-ku-ra ri-li-pa ra-ma-pu hu-tia kia hi-ni pa-pa ha-ni ra-ne koa

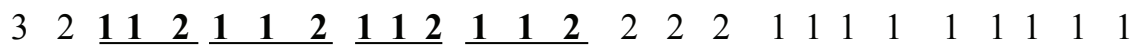

In the phrase exemplified, the light of the full moon reveals the nakedness of the Hirane women and in the following phrases goes on to shine upon female inhabitants of other areas along its path. Further, a suitable prelude to sexual intimacy was described in the narrative preceding this sequence as Kaloma Koli and Kundaleme danced together and set off planning to spend the night in each other's company. Thus, this extended moon/sun sequence can be interpreted as 
alluding to a potential for courting and sexual activity. Given this context, it is striking to observe the predominance of the tones 3 and 2 in an alternating pattern in this example: this exact pitch pattern, followed by a prolonged 1 with adjacent pitch 2, is the identifying melodic feature of the Duna courting genre yekia, also known as laingwa (see Stewart and Strathern 2002:77-87). ${ }^{13}$ Kiale's use of melodic (and textual) structures that are characteristic of a performance genre specifically concerned with attracting a sexual partner perhaps strengthens the textual and thematic allusion to courting and sex, topics which are likely to engage the imaginative and personal interest of the listeners during these interludes (as well as spark ribald banter).

\section{Audience response}

As we have seen in the previous examples, the text of the ground section in particular tends to be imaginatively evocative, building on the information provided in the descent section, and provoking the hearers to engage with the story as something to construct for themselves. Such active engagement can be prompted by the necessity of interpreting oblique imagery and esoteric vocabulary, and through the encouragement to "envision" the narrated activity from within the narrated world. The melodic contour of the ground section, in conjunction with the use of kẽiyaka vocabulary may also be evocative in another sense, as it can reference other recognizable Duna performance genres that are appropriate to occasions of intense personal feeling, such as deep sorrow or sexual excitement. We return here to a closer consideration of this audience response to and identification with the pikono, particularly as it is externalized through utterances that accompany the performance.

Vocalized responses of a pikono audience typically occur either during or following the ground section of a phrase. They can take a variety of forms, for example, wordless exclamations, conventionalized sound patterns (e.g., representing birdcalls), conventional phrases (home kone, meaning roughly 'exactly so'), prompts to the performer, or free-form comments on the narrative. These interjections are generally called or spoken (e.g., as opposed to being sung) and are usually independent of the pitches articulated by the performer. Duna pikono audience responses thus contrast to those of the Huli genre bi té, where regular audience interjections are typically highly constrained in terms of their form and placement (see Lomas, this volume), and are usually pitched at the tonal centre established by the singer (Pugh-Kitingan 1981:332-33).

13 A thematic parallel can also be proposed in that it is in these passages that the performer most clearly exhibits his virtuosity in rapidly listing a great number of kẽiyaka terms. This can be compared to a function of yekia in which the singing men try to impress a potential partner, for example, through persuasive reference to their land's richness and ripeness. 
Audience responses can assert a close involvement with the narrative. For example, the audience member's call, keno nganda! ('we two will go!'), in text 1 expresses a complete identification of the speaker with a character in the narrative - that is, he speaks for Kaloma Koli in reply to the persuasive argument of Kundaleme to travel with her. Alternatively, audience comments may bring the narrative into the performance setting. In the sun/moon sequences, the audience waits expectantly for the light of the sun or the moon to pass over familiar lands, or even over the place where they now sit listening to a pikono performance. This is the case in text 2, where as the light of the moon reaches Hirane (where Kiale's performance is taking place) and shines upon the naked women, an audience member calls out, ndu narayani! ('there's not one here!').

As is strongly evident in text 2 , it is within the ipakana yakaya sequences of the ground section of a phrase that reference to real-world places is most strongly and consistently made. Identifiable places can be a major touchstone for a personal response to the performance. ${ }^{14}$ The "action" of the narrative may be new, mirrored in the unpredictability of the melodic variations of the descent section, but locations referenced by kẽiyaka are often intimately known, coinciding with predictable melodic and textual structures. Audience members' responses can reinforce their strong personal connection with places, for example, when they themselves contribute kẽiyaka terms to the performance, prompting Kiale and declaring their knowledge of and relationship to the location that is being named.

\section{Conclusion}

Close analysis of the music and language of sung pikono contributes to an understanding of the performance at several levels. Pitch and text delineate essential structural units of pikono, identified here as a higher-level unit, the phrase, which is composed of two further units, the descent and ground. The descent tends to introduce new information, whereas the ground repeats what is already familiar.

Distinctive musical and linguistic features of the ground section (in contrast to the descent) include: a narrow and predictable melodic range; sonic repetition (of both pitches and phones); increased use of grammatical "viewpoint" markers;

14 Kendoli (this volume) comments on the function of places as linking a pikono story to one's own memories, as hearing them named reminds the hearer of times they have spent in these (or similar) areas. Kendoli also mentions that the places named in pikono commonly include currently uninhabited areas, and he elaborated on this (pers. comm., 7 March 2007) as typically including areas of previous settlement. He pointed out that hearing about these areas provokes a sense of nostalgic longing, as one remembers that recent ancestors once lived here but have since passed away, leaving unpeopled tracts of land resonant with family history. This theme is re-enforced in the pikono narrative, as it is common for a hero to come upon abandoned settlements during his travels. The desolate house and garden is in fact a recurring motif in several Duna narrative genres as a site of mystery, regeneration, and reunion. 
pointed reference to real-world locations; and allusion to other Duna performance genres through the use of kẽiyaka vocabulary in combination with recognizable melodic formulae. These features may encourage a listener to experience the ground section as a place to absorb and become absorbed in the narrative content and imagery introduced in the descent, and build a close involvement in the pikono. This imaginative and emotional engagement can inspire a pikono audience to actively contribute to the performance as a soundscape, a story, and an expressive and personally moving event.

\section{References}

Aikhenvald, Alexandra. 2004. Evidentiality. Oxford: Oxford University Press.

Chafe, Wallace, and Johanna Nichols. 1986. Evidentiality: The Linguistic Coding of Epistemology. Norwood, NJ: Ablex Publishing Corporation.

Chenoweth, Vida. 1969. "An Investigation of the Singing Styles of the Dunas." Oceania 39 (3): 218-30.

de Vries, Lourens. 2005. "Towards a Typology of Tail-head Linkage in Papuan Languages." Studies of Language 29: 363-84.

Giles, Glenda. 1972. "Duna is Not Greek, But How Far Can One Go?” The Bible Translator 23 (4): 406-12.

Gillespie, Kirsty. 2010a. "Giving Women a Voice: Christian Songs and Female Expression at Kopiago, Papua New Guinea.” Perfect Beat 11 (1): 7-24.

- 2010b. Steep Slopes: Music and Change in the Highlands of Papua New Guinea. Canberra: ANU E Press. http://epress.anu.edu.au/steepslopes_ citation.html.

Haley, Nicole. 2002. “Ipakana Yakaiya: Mapping Landscapes, Mapping Lives; Contemporary Land Politics among the Duna." PhD dissertation, Australian National University.

Hogbin, H. Ian, and Camilla H. Wedgwood. 1953. "Local Grouping in Melanesia." Oceania 23 (4): 241-76.

Modjeska, Charles J. Nicholas. 1977. "Production among the Duna: Aspects of Horticultural Intensification in Central New Guinea." PhD dissertation, Australian National University. 
Pugh-Kitingan, Jacqueline. 1981. "An Ethnomusicological Study of the Huli of the Southern Highlands, Papua New Guinea.” PhD dissertation, University of Queensland.

San Roque, Lila. 2008. “An Introduction to Duna Grammar.” PhD dissertation, Australian National University, Canberra.

Stewart, Pamela J., and Andrew Strathern. 2000. "Naming Places: Duna Evocations of Landscape in Papua New Guinea." People and Culture in Oceania 16: 87-107.

- 2002. Gender, Song and Sensibility: Folksongs and Folktales in the Highlands of New Guinea. Westport, CT: Praeger.

, eds. 2005. Expressive Genres and Historical Change: Indonesia, Papua New Guinea and Taiwan. Anthropology and Cultural History in Asia and the Indo-Pacific Series. Hants: Ashgate.

Strathern, Andrew, and Pamela J. Stewart. 2004. Empowering the Past, Confronting the Future: The Duna People of Papua New Guinea. Contemporary Anthropology of Religion Series. New York: Palgrave Macmillan.

Stürzenhofecker, Gabriele. 1998. Times Enmeshed: Gender, Space and History among the Duna of Papua New Guinea. Stanford, CA: Stanford University Press. 